\title{
Influence of differential with the limited gear ratio on the efficiency reflecting losses on wheel slip
}

\author{
Andrey Efimov ${ }^{1,}$, Sergey Kireev ${ }^{1}$, Marina Korchagina ${ }^{1, *}$, Alexey Lebedev ${ }^{1}$, Khaidar \\ Kaderov $^{1}$ \\ ${ }^{1}$ Don State Technical University, sq. Gagarina, 1, Rostov-on-Don, 344010, Russia
}

\begin{abstract}
At vehicle movement, there are two factors that specify conflicting requirements for transfer box drive and axle drive. Let's describe them: each wheel rotating at different speeds and reduced adherence of one or more wheels. The road conditions: the decrease in friction and kinematic disparity, acting often at the same time, present conflicting requirements to drive of the driving wheels. These factors tend to be of time-varying nature. The nature of the studied processes is transient; it will be influenced by the inertia, stiffness and damping properties of the vehicle power train parts. The efficiency reflecting losses on wheel slip is proposed as a uniform selection criterion of an interaxial drive. Based on comparison of dependence of this parameter on road conditions, higher efficiency of differential with limited gear ratio compared to simple differential and blocked drive is shown. The chosen approach on the basis of quantitative indices proves the efficiency of differential with the limited transfer ratio in comparison with other main types of the drive, such as differential and blocked.
\end{abstract}

\section{Introduction}

The road conditions: the decrease in friction and kinematic disparity, acting often at the same time, present conflicting requirements to drive of the driving wheels.

As it is noted in [1-9] nowadays there is no uniform criterion for evaluation of efficiency of an interaxial drive. This article [10] proposes that the coefficient of efficiency reflecting losses on wheel slip is such a criterion.

\section{Methods}

There you can find the following formula for calculation of the coefficient of efficiency reflecting losses on wheel slip during time period from 0 to $\mathrm{T}$ :

\footnotetext{
*Corresponding author: ms.korchaginamv@mail.ru
} 


$$
\eta_{\delta}^{\text {mean }}=\int_{0}^{T} \eta_{\delta} d t
$$

where $\eta_{\delta}$ is the coefficient of efficiency reflecting losses on wheel slip, accepting various values during time period from 0 to $\mathrm{T}$ :

$$
\eta_{\delta}=1-\frac{N_{\delta 1}+N_{\delta 2}}{N_{K}}
$$

where $N_{\delta 1}, N_{\delta 2}$ are the capacities lost on slipping, respectively, by wheels of front and back axles.

$N_{K}$ is the power brought to the driving axles.

\section{Research}

We used mathematical model of the vehicle described in this article [11] for the research.

In Fig. 1 you can see the dependence of the coefficient of efficiency mean value reflecting losses on wheel slip in all range of road conditions for the vehicle with the differential interaxial drive.

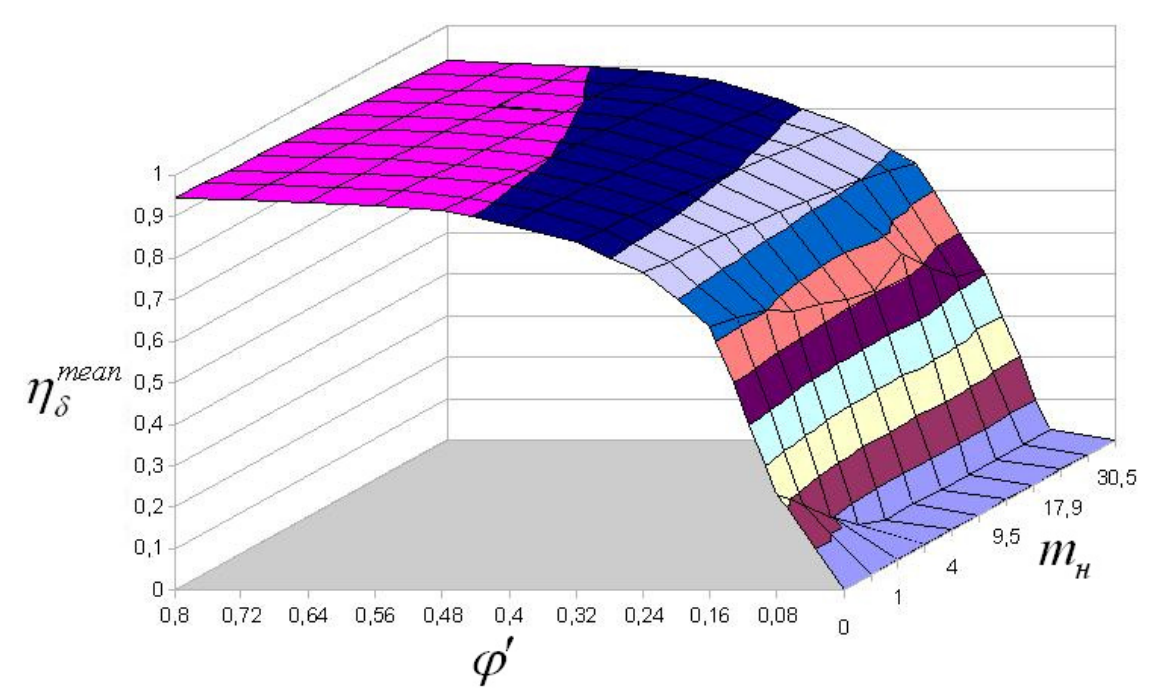

Fig. 1. Dependence of the efficiency mean value, reflecting losses on wheel slip with the differential interaxial drive.

Where $\eta_{\delta}^{\text {mean }}$ is the coefficient of efficiency reflecting losses on wheel slip; 
$m_{H}$ is the disparity coefficient;

$\varphi^{\prime}$ is the friction coefficient of the slipping axle.

You can see from the graph that increase in kinematic disparity practically does not influence vehicle efficiency with the differential drive. Decrease in friction causes considerable decrease in the efficiency reflecting losses on slipping for the vehicle with the differential interaxial drive. The efficiency zero values, reflecting losses on slipping, mean impossibility of movement under these road conditions with the considered type of the interaxial drive.

In Fig. 2 you can see the dependence of the coefficient of efficiency mean value reflecting losses on wheel slip in all range of road conditions for a vehicle with the blocked interaxial drive.

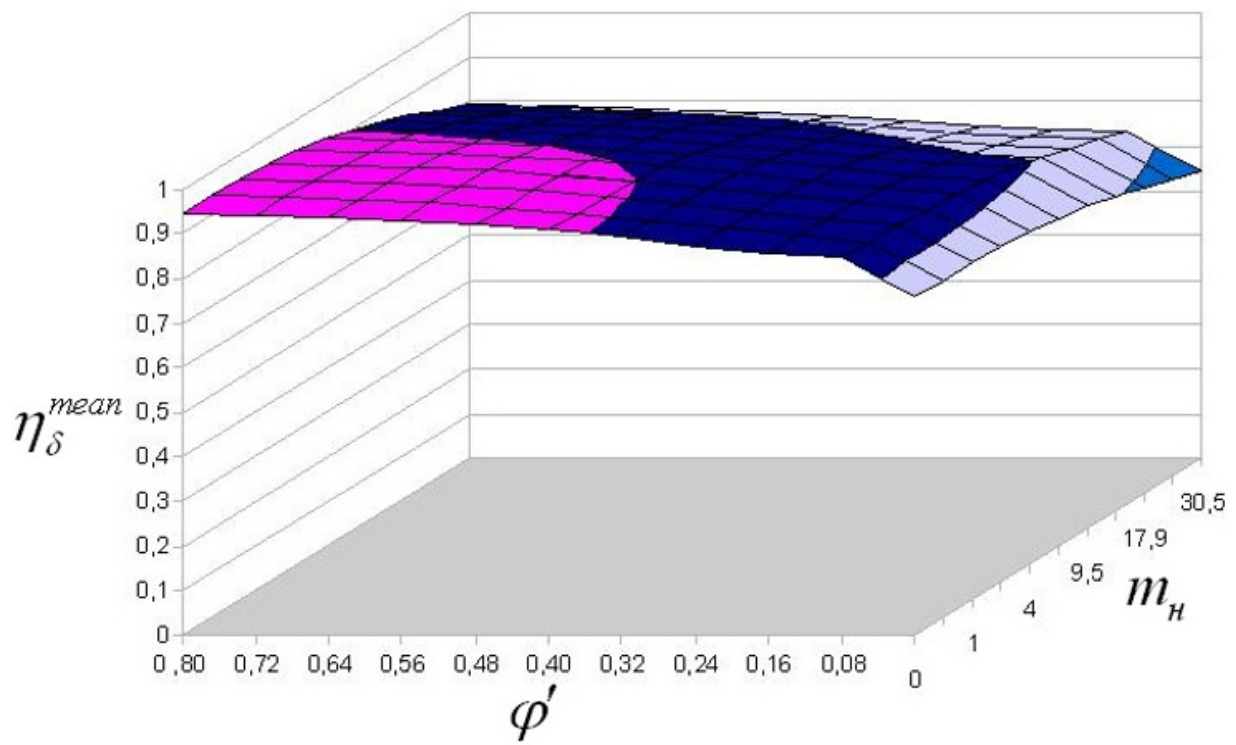

Fig. 2. Dependence of the efficiency mean value, reflecting losses on wheel slip, with the blocked interaxial drive.

Where $\eta_{\delta}^{\text {mean }}$ is the coefficient of efficiency reflecting losses on wheel slip;

$m_{H}$ is the disparity coefficient;

$\varphi^{\prime}$ is the friction coefficient of the slipping axle.

It is characteristic of the vehicle with the blocked drive to have noticeable decrease in efficiency values. They reflect losses on wheel slip with increase in kinematic disparity, caused by circulation of parasitic power in the transmission. On the graph you can see that the efficiency, reflecting losses on wheel slip, decreases with decrease in friction, but this decrease is much less in comparison with efficiency values of the vehicle with the differential interaxial drive.

In Fig. 3 you can see the dependence of the coefficient of efficiency mean value reflecting losses on wheel slip in all range of road conditions for the vehicle equipped with differential with the limited transfer relation. 


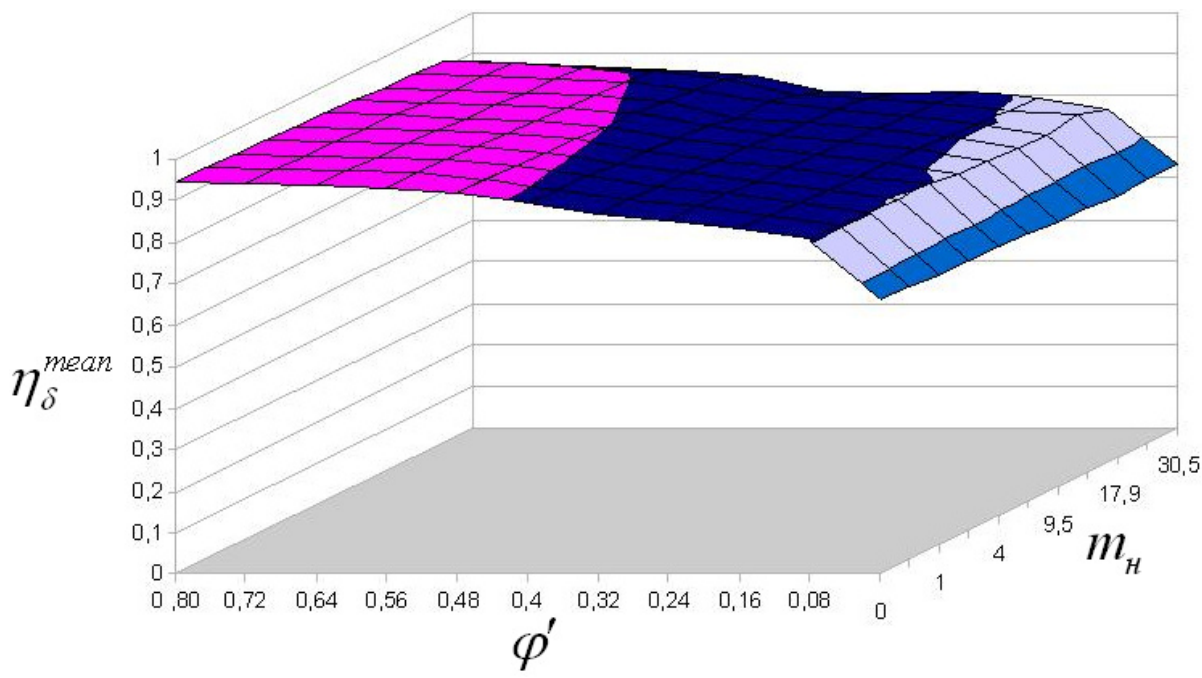

Fig. 3. Dependence of the efficiency mean value, reflecting losses on wheel slip, for the vehicle equipped by differential with the limited transfer ratio.

Where $\eta_{\delta}^{\text {mean }}$ is the coefficient of efficiency reflecting losses on wheel slip;

$m_{H}$ is the disparity coefficient;

$\varphi^{\prime}$ is the friction coefficient of the slipping axle.

Let us consider the influence of automatic blocking of interaxial differential (such as described here [12], or such as Ferguson drive of automobile Jensen CV-8FF [13]) on the efficiency reflecting losses on wheel slip. This mechanism is as follows: the differential with the mechanism of automatic blocking belongs to a type of differentials with the limited transfer ratio. The following situation is characteristic of this type of the drive: during putting into operation the blocking of differential of a wheel, the speeding and lagging behind wheels continue to rotate with different angular speeds, but the ratio of angular speeds of the speeding and lagging behind wheels does not increase any more.

It is characteristic of the vehicle equipped with differential with the limited transfer ratio that the coefficient of efficiency reflecting losses on slipping practically does not reduce the value during increase in kinematic disparity. In this part dependence is the same as for the vehicle with the differential drive. At the same time, one can observe smaller decrease in the efficiency reflecting losses on wheel slip during decrease in friction in comparison with the differential drive. Thus, automatically blocked interaxial differential combines the advantages both of differential and the blocked drive, and at the same time it lacks the flaws characteristic to them. Below in the Table, we give the comparison of the efficiency mean values, reflecting losses on slipping and the road conditions calculated for all ranges In the Table you can see that the differential with the limited transfer ratio has the largest mean value of the coefficient of the efficiency reflecting losses on wheel slip. 
Table. 1 The efficiency reflecting losses on wheel slip, in all range of road conditions for vehicles, with various types of the drive

\begin{tabular}{|l|c|c|c|}
\hline $\begin{array}{l}\text { Type of the } \\
\text { interaxial drive }\end{array}$ & Differential & Blocked drive & $\begin{array}{l}\text { The differential } \\
\text { with the limited } \\
\text { gear ratio }\end{array}$ \\
\hline $\begin{array}{l}\text { The efficiency } \\
\text { reflecting losses } \\
\text { on wheel slip }\end{array}$ & $\mathbf{0 , 6 8 8}$ & $\mathbf{0 , 8 4 7}$ & $\mathbf{0 , 8 5 2}$ \\
\hline
\end{tabular}

\section{Conclusions}

1. The received dependences correspond to the known data on properties of the differential and blocked drive that validates the chosen approach.

2. The offered criterion allows carrying out the choice like the interaxial drive on the basis of quantitative comparison of indicators.

3. The chosen approach on the basis of quantitative indices proves the efficiency of differential with the limited transfer ratio in comparison with other main types of the drive, such as differential and blocked.

\section{References}

1. G.B. Shipilyevsky, Automobile industry, 2, 7-10 (2016)

2. V.V. Anchukov, A.S. Alyukov. South Ural State University, 3, 68-79 (2018)

3. A.V. Kotovskov, Vehicle differential lock mechanism, Patent RUS 131112 (2013)

4. A.V. Keller, Vehicle center differential lock control, Patent RUS 177736 (2017)

5. A.V. Keller, V.V. Keller, Vehicle center differential lock control, patent RUS 173803 (2017)

6. I.I. Bogdanova, Automobile industry, 6, 12-14 (2015)

7. A.V. Murzin, Automobile industry, 4, 15-17 (2014)

8. A.Yu. Barykin, Automobile industry, 12, 11-12 (2013)

9. A.V. Krutashov, Automobile industry, 1, 11-13 (2011)

10. A.V. Efimov, S.O. Kireev, M.V. Korchagina, Dynamic of Technical Systems (2018)

11. A.V. Efimov, S.O. Kireev, M.V. Korchagina. Problems of machine building and machine reliability, 1, 94-100 (2018) 